\title{
Liquid foraging behaviour in leafcutting ants: The lunchbox hypothesis
}

\author{
Rytter, Winnie ${ }^{\mathrm{a}^{*}}$ \& Shik, Jonathan Zvi ${ }^{\mathrm{a}, \mathrm{b}}$ \\ ${ }^{a}$ Centre for Social Evolution, Department of Biology, University of Copenhagen, \\ Copenhagen, Denmark \\ ${ }^{\mathrm{b}}$ Smithsonian Tropical Research Institute, , Ancon, Panama \\ *Corresponding author: W. Rytter, Centre for Social Evolution, Department of Biology, \\ University of Copenhagen, Universitetsparken 15, 2100 Copenhagen, Denmark \\ winnie.rn@hotmail.com \\ Type of manuscript: Research Article \\ \# of Words in Abstract: 232/300 \\ \# of Words in manuscript, literature cited and figure captions: 5615 \\ \# of Tables and Figures: 4 Figures, 1 Table \\ \# of electronic supplementary elements: Table A1, Table A2
}

\section{KEYWORDS:}

Attine

Ant colony

Optimal foraging theory

Proventriculus

Social stomach 
Efficient food acquisition is a central challenge faced by organisms, and optimal

2 foraging theory (OFT) explores the ways natural selection has fine-tuned foraging strategies

3 to meet this challenge, maximising food harvest while minimising foraging time and

4 exposure to predators (Stephens, Brown \& Ydenberg, 2007; Stephens \& Krebs, 1986). OFT

5 models typically weigh energetic dietary gains relative to energetic foraging costs and predict

6 reduced fitness with excessively costly or unsuccessful foraging trips (Pyke, Pulliam \&

7 Charnov, 1977). However, it is often not feasible to directly observe foraging dynamics

8 including ecological processes related to ingestion (e.g. food capture and transport) and

9 physiological processes related to digestion (e.g. food assimilation). This means that me

10 asuring foraging success, and thus testing OFT models, can be difficult even with inferential

11 techniques (e.g. stable isotopes; Feldhaar, Gebauer \& Blüthgen, 2009).

Many animals are 'central place foragers' and a specific set of OFT models has

helped understand how they overcome issues like local resource depletion when repeatedly

14 returning harvested resources to a central nest or sleeping site (Orians \& Pearson, 1979; Oster

15 \& Wilson 1978; Stephens \& Krebs, 1986). Ant colonies have provided model systems for

16 testing OFT predictions because they are central place foragers that use diverse collective

17 foraging behaviours to locate, defend, and transport resources back to stationary nests

18 (Lanan, 2014; Oster \& Wilson, 1978; Roces \& Núñez, 1993). Moreover, individual workers

19 dynamically adjust foraging behaviours when harvesting resources with varied nutritional

20 compositions (Dussutour \& Simpson, 2008; Kay, 2002; Portha, Deneubeourg \& Detrain,

21 2002) and physical properties (Robson \& Traniello, 1998). For instance, many ants carry

22 protein-rich insect prey in their mandibles and transport carbohydrate-rich liquids (e.g. nectar

23 from plants or insect symbionts) within three connected specialised storage organs (crop,

24 midgut, hindgut; Fig. 1) (Engel, Fischer, Wäckers \& Völkl, 2001; Josens, Farina \& Roces, 25 1998). 
In colonies where solid food is most commonly harvested, foragers returning full of

27 liquids can appear 'unladen', or lacking harvested resources, and thus be erroneously

considered energetic drains on their colonies. However, these liquid resources support an ant

colony's 'social stomach', with a digestive adaptation called the proventriculus (Fig. 1c),

enabling workers to regurgitate liquids and share them with nestmates (Cook \& Davidson,

2006; Eisner, 1957; Eisner \& Brown, 1958). Leafcutter ants (Attini; genera Atta and

Acromyrmex) are the most evolutionarily derived fungus-farming attine ants, cutting and

transporting mostly fresh vegetation they prepare as compost to cultivate fungus crops for

food in subterranean nests (Hölldobler \& Wilson, 2010). Leafcutter foragers often transport loads optimised in size and shape to their individual foraging abilities (Lewis, Pollard \&

Dibley, 1974; Wetterer, 1994, 1995). However, foraging trips also often appear unsuccessful as foragers return without carrying any vegetation (Araújo, Lucia, Lima, Souza \& Petternelli, 2002; Lewis, et al., 1974, but see Kooij, et al., 2014). While these unladen foragers appear to present efficiency problems relative to OFT predictions, they have alternatively been hypothesised to lead nestmates to high-quality resources (Bollazzi \& Roces, 2011; Jaffe \& Howse, 1979; Roces \& Núñez, 1993), or maintain foraging trails (Lewis, et al., 1974). Unladen leafcutter foragers have also frequently been assumed to transport, consume, and assimilate liquid resources in the form of carbohydrate-rich plant nectar (Bass \& Cherrett, 1995; Littledyke \& Cherrett, 1976; Mueller, Schultz, Currie, Adams \& Malloch, 2001; Wirth, Herz, Ryel, Beyschlag \& Hölldobler, 2003), but no direct evidence has been provided that this happens routinely in the field. While many ant lineages are known to consume nectar or similar plant secretions (Hölldobler \& Wilson, 1990), it has remained underappreciated that specialised fungivory may constrain opportunities to maintain a complementary generalist feeding strategy. Indeed, since the digestive system of 
51 garden growth via fecal droplets (De Fine Licht, et al., 2013; Kooij, et al., 2014; Martin, 1970; Schiøtt, Rogowska-Wrzesinka, Roepstorff \& Boomsma, 2010), opportunistic foraging on other liquids would likely destabilise this fine-tuned system. A likely alternative is that while nectar foraging does not occur, the possibility has remained plausible as no study has used dissections to remove the thick, opaque abdominal exoskeleton and confirm the presence or absence of liquids in storage organs of unladen workers returning to the nest (Fig. 1a).

We first used dissections of four Panamanian rainforest leafcutter species to test the OFT prediction that unladen leafcutter ants actually represent successful foraging trips because they are more likely to harvest liquids. We initially established baseline levels of liquid storage in foragers collected as they left their nests, reasoning that if returning foragers had excess liquids above this baseline, they harvested them outside the nest. This led to the surprising observation that most foragers carried liquids in their midguts when exiting their nests, which, in turn led us to perform additional experiments testing a newly formalised 'lunchbox hypothesis'. Below, we develop this hypothesis within an OFT framework, outlining how it integrates digestive physiology, energetic foraging costs, and symbiotic stability.

The lunchbox hypothesis provides an OFT prediction that foraging leafcutter ants leave nests with full midguts, which they deplete to fuel energetically costly foraging activities. These energetic costs include the cutting of leaves, which requires extreme mandibular forces (Roces \& Lighton, 1995), foraging trips extending >200 meters from the nest (Lewis, et al., 1974), and the transport of heavy loads (Lighton, Bartholomew \& Feener,

73 1987) weighing more than double the body mass of a forager (Wetterer, 1994). Whereas

74 nectar foraging would appear at odds with the specialised interplay between ant farmers and 75 fungal crops, lunchbox dynamics would provide a powerful nutritional mechanism 
integrating the performance of symbiotic partners, as fungi would fuel ant foragers to perform foraging tasks needed to harvest resources that fuel fungal growth. We tested the lunchbox prediction that liquid depletion reflects task performance using a series of laboratory experiments manipulating foraging distance, load mass, and leaf-cutting activity.

\section{METHODS}

Liquid Transport in Field-Collected Foragers

We observed foraging behaviour in a rainforest within Soberania National Park, Panama (N 9.15451, W 79.73583) in May 2015, during the start of the rainy season, a period of high leafcutter activity. We observed four sympatric leafcutter species: Acromyrmex echinatior (5 colonies), Acromyrmex octospinosus (3 colonies), Atta colombica (3 colonies), and Atta sexdens ( 3 colonies). This sampling effort is similar to other studies on leafcutter foraging dynamics (e.g. Burd \& Howard, 2005; Lopes, Forti \& Camargo, 2004).

We counted the number of laden and unladen foragers returning to nests in focal observations that were $\geq 30$ minutes for Acromyrmex (Ac. echinatior, $\mathrm{n}=8 ;$ Ac. octospinosus, $\mathrm{n}=4$ ) and 3 minutes for Atta (At. colombica, $\mathrm{n}=6$; At. sexdens, $\mathrm{n}=6$ ). This sampling effort yielded a total of 374 observation minutes for Ac. echinatior (365 returning ants), 151 minutes for Ac. octospinosus (130 returning ants), 18 minutes for At. colombica (2 679 returning ants), and 18 minutes for At. sexdens (2 078 returning ants). Colonies of Atta (ca. 100 workers per minute) had far more workers foraging per minute than Acromyrmex (ca. 1 worker per minute), which necessitated both shorter foraging observation windows and the use of video recordings to accurately capture the laden vs. unladen worker foraging dynamics (Table A1). We thus counted Acromyrmex workers directly in the field and video recorded foraging Atta trails with an iPhone 4S, slowing the recordings to 15 frames per second in VLC media player (v2.2.1). We calculated mean per cent of unladen returning foragers (not 
carrying any substrate in their mandibles) per observation period, per colony, per species $( \pm$ $\mathrm{SE})$.

We next tested whether unladen returning foragers were more likely to transport

104 liquid resources, collecting foragers from three categories (laden returning, unladen returning,

105 and exiting the nest), and returning them to the lab in separate containers for dissections to 106 determine empty/full status of liquid storage organs (crops, midguts, hindguts; Fig. 1). Soon 107 after being returned to the lab, foragers were secured under water in wax-filled petri dishes under a dissecting microscope (160X magnification) and their abdomens opened with \#5 watchmaker forceps. Full storage organs had a characteristic distended appearance and were usually filled with yellow fluid (Fig. 1). Since repeated dissections of workers were not

111 possible, we used the following logic to infer that liquids were harvested outside the nest.

112 First, we established baseline liquid storage dynamics by collecting exiting workers

113 immediately upon leaving their nests for foraging trips. Second, if returning workers had 114 more stored liquids than exiting workers, we inferred these represented liquids harvested 115 outside the nest.

$116 \quad$ We dissected $8.33 \pm 0.88$ Acromyrmex foragers and $18.80 \pm 1.29$ Atta foragers per 117 foraging category, per collection event, and dissected a total of 670 foragers (Ac. echinatior: 118 161, Ac. octospinosus: 114, At. colombica: 200, At. sexdens: 195). We selected the 'typically' 119 sized forager for each species (Hughes, Summer, Van Borm \& Boomsma, 2003; Moreira, et 120 al., 2010), measuring the headwidth (HW in $\mathrm{mm}$ ) from eye to eye for all dissected ants (Ac. 121 echinatior: $2.2 \pm 0.2$, Ac. octospinosus: $2.3 \pm 0.3$, At. colombica: $2.3, \pm 0.3$ At. sexdens: $2.1 \pm$ 122 0.3). Thus, while Atta species are distinct from other attines in having substantial intracolony 123 variation in worker body size corresponding to task specialisation (Hölldobler \& Wilson, 124 2010; Wilson, 1980), we compared similarly sized workers across all colonies in the present 125 study. 
with an underlying Gaussian distribution testing whether the proportion of individuals with

full storage organs varied with foraging status (laden, unladen, exiting), storage organ (crop,

129 midgut, hindgut), and species identity (Ac. echinatior, Ac. octospinosus, At. colombica, At.

130 sexdens). To account for multiple sampling events for some colonies, we included colony ID

131 as a random factor nested within species. We evaluated significant results here and in all tests described below with post-hoc multiple comparison tests, applying Holm-Tukey adjustment of observed p-values to control for Type I error.

\section{Liquid Transport and Foraging activity: The Lunchbox Hypothesis}

To test the lunchbox hypothesis, we performed a series of laboratory experiments on three intact Ac. echinatior colonies (Ae276, Ae342, Ae480) collected from Panama, and maintained at the University of Copenhagen in a climate-controlled room $\left(25^{\circ} \mathrm{C}\right.$ and $75 \%$ $\mathrm{RH})$ housed in plastic nest boxes $(38 \times 28 \mathrm{~cm})$ with fluon-coated walls. We first dissected

140102 foragers collected immediately after they exited the nests to establish baseline liquid

141 transport frequencies (full vs. empty) in crops (41\% full), midguts (91\% full), and hindguts

142 (91\% full). We then tested whether foragers depleted more liquids with increasing foraging 143 distances, load weights, and leaf-cutting activity.

144 In a full-factorial design, we first compared liquid transport status in foragers varying 145 in load mass (no load vs. $10 \mathrm{mg}$ load) and foraging distance ( $2 \mathrm{~m}$ vs. $10 \mathrm{~m}$ ). Colonies were 146 connected via a removable bridge to a 'middle box' that was connected to a foraging arena 147 via clear $1 \mathrm{~cm}$ inner diameter tygon tubing. We manipulated foraging distance by connecting 148 middle boxes and foraging arenas with $2 \mathrm{~m}$ or $10 \mathrm{~m}$ lengths of tubing. Laden foragers had a $14910 \mathrm{mg}$ clay ball affixed to their dorsal thoracic spines (Lighton, et al., 1987; Wetterer, 1995)

150 while 'unladen' control foragers lacked a clay ball. The clay ball was gently affixed 
immediately after removing foragers from the empty foraging arena, and they were then

152 placed back in the arena. We collected and dissected returning foragers as soon as they

153 reached the middle box on their way back to the colony. We quantified the effects of

154 experimental handling on liquid storage, comparing liquid storage in workers seconds after

155 affixing the clay ball $(\mathrm{n}=30)$ with control workers having just left their nest to forage $(\mathrm{n}=$

156 30). Handling treatment did not significantly affect the overall presence of stored liquids

$157\left(\mathrm{~F}_{2,174}=0.01 ; \mathrm{p}=0.910\right)$, nor did handling effects vary across organs $\left(F_{2,174}=1.36 ; P=\right.$ $1580.261)$

Prior to experiments, we placed blackberry leaves (Rubus sp.) in the foraging arena

160 for $\geq 5$ hours so colonies would establish foraging trails inside the tube. When collecting

161 foragers for the experiment, we removed the leaves to avoid potential liquid harvest resulting in exiting foragers arriving to an empty foraging arena. We then collected foragers as they arrived in the arena to use for load mass manipulation. Although leafcutters are known to

164 carry loads of $>10 \mathrm{mg}$ (Cherrett, 1972), the load mass we used approximated the average leaf 165 fragment weight $(9.3 \pm 1.03 \mathrm{mg}, \mathrm{n}=24)$ transported by laden Ac. echinatior foragers in the

166 lab colonies. We used the GLIMMIX procedure as described above to test for differences in 167 the proportion of individuals with full storage organs across load mass treatments $(0,10 \mathrm{mg})$,

168 distance treatments (2,10 m), and storage organs (crop, midgut, hindgut), with colony ID

169 included as a random factor. As above, we modelled residual variance with storage organ as a 170 repeated factor, with a covariance structure based on separate residual variances for each

171 organ and residual covariance between two adjacent organs moving from the crop to midgut 172 to hindgut.

173 We tested whether foragers depleted transported liquids when cutting leaves. We 174 allowed foragers from five colonies (Ae332, Ae376, Ae430, Ae490, Ae507) to access the 175 middle box containing a small branch with blackberry leaves. We collected foragers for 
dissection immediately after they finished cutting a leaf fragment $(n=84)$ and compared their

177 liquid status to exiting control foragers collected just after leaving the nest $(n=78)$. We used

178 the same statistical approach described above to test for differences in proportions of

179 individuals with full storage organs (crop, midgut, hindgut) depending on leaf-cutting activity

180 (cutting, exiting).

181

Ethical Note

183

Dissections were necessary to test the hypothesis of liquid foraging, since leafcutter

184 ants have thick, opaque cuticle (Fig. 1). However, sacrificed individuals represented an

185 exceedingly small fraction of overall colony populations (e.g. 40 workers from colonies with

186 millions of workers). Thus, the present study did not harm leafcutter ant colonies that were observed in the field (remain intact in Panama) or lab (maintained in Copenhagen), as all colonies continued to forage normally after the experiment, and in no case was the queen harmed. Prior to dissections, ants were secured unconscious underwater in a wax filled dish, and workers were transferred to $95 \% \mathrm{EtOH}$ as soon as observations were complete.

\section{RESULTS}

Liquid Foraging Behaviour in the Field

Unladen workers without any substrate in their mandibles were common across four

195 leafcutter species, representing $>41 \%$ of all 5252 returning workers observed during $>500$

196 minutes of field observations (Fig. 2). Colonies of Ac. echinatior had $1.17 \pm 0.31$ returning

197 ants per minute, $38.1 \%$ of which were unladen, while Ac. octospinosus had $0.96 \pm 0.22$ ants

198 per minute, $31.2 \%$ of which were unladen (Fig. 2). Colonies of At. colombica had $148.83 \pm$ 19930.57 returning ants per minute, $48.1 \%$ of which were unladen foragers, while At. sexdens 
had an average foraging rate of $115.44 \pm 35.19$ returning ants per minute, $44.7 \%$ of which were unladen (Fig. 2).

Liquid transport behaviours in the field did not vary significantly across leafcutter species $\left(F_{3,10.99}=0.42, P=0.744\right.$; Table 1$)$, but liquid transport varied across storage organs depending on foraging status $\left(F_{4,50.94}=5.10, P=0.002\right.$; Table 1; Fig. 3). Specifically, foragers tended to exit nests with full midguts and return with depleted midguts when laden with vegetation (Fig. 3, Table A2). Moreover, foragers were more likely to transport liquids in their midguts than their crops (Fig. 3; Table A2), but the likelihood of transporting liquids in their midguts and hindguts was not significantly different (Fig. 3; Table A2), indicating low potential of transport for sharing with nestmates because digestion is unidirectional after passing through the proventriculus. Laden returning foragers also tended to have fuller hindguts than midguts (Fig. 3; Table 1; Table A2), suggesting foraging work involved the assimilation of liquids from the midguts and transfer of waste to the hindgut.

Liquid Transport and Foraging Behaviour: The Lunchbox Hypothesis across storage organs and foraging activities. First, as in the field, foragers more frequently carried liquids in their midguts and hindguts than in their crops $\left(F_{2,7.91}=202.91, P=0.0001\right.$; Table 1), with ca. $22 \%$ foragers having crop liquids compared to ca. $83 \%$ foragers having midgut liquids (Fig. 4). Second, experimentally laden workers transported liquids in all storage organs less frequently than unladen foragers $\left(F_{1,10.63}=17.46, P=0.002\right.$; Table 1$)$, regardless of whether they foraged $2 \mathrm{~m}$ or $10 \mathrm{~m}\left(F_{1,10.63}=2.55, P=0.139\right.$; Table 1 ; Fig. 4$)$. Third, leaf-cutting activity did not significantly reduce overall liquid storage $\left(F_{1,12.84}=0.99\right.$, $P=0.338$; Table 1), or midgut-specific liquid storage $\left(F_{2,7.204}=0.61, P=0.569\right.$; Table 1$)$. 


\section{DISCUSSION}

This study tests whether the OFT prediction that individuals forage to maximise

227 energetic returns holds when the foragers belong to a highly derived symbiosis that would

228 likely be destabilised by such foraging decisions. Field observations and laboratory

229 experiments confirm that leafcutter ants do not forage for liquid nectar and thus question the

230 decades-old assumption that they acquire nutrition from sources other than their tightly co-

231 evolved fungal cultivars. Moreover, while over $40 \%$ of the foragers in four sympatric

232 leafcutter species returned to their nests without leaf fragments, these unladen ants were not

233 more likely to carry liquids. Instead, we find support for the lunchbox hypothesis because

234 most workers left nests with midguts full of liquids that were depleted (assimilated and

235 transferred to hindguts) if workers returned with a leaf fragment in the field or transported a

236 load in lab experiments. Thus, in contrast to the destabilising effects of external nectar

237 foraging, these results provide a novel mechanism promoting symbiotic stability, as fungi

238 provide fuel for foragers to harvest more substrate for fungal crop production.

Such nutritional feedbacks likely govern the ecological success of the leafcutter

240 symbiosis, dominant herbivores in habitats across the New World tropics and subtropics

241 (Wirth, et al., 2003). Specifically, leafcutter ants produce a highly 'domesticated' fungal

242 cultivar Leucoagaricus gongylophorus that no longer grows freely in the wild (Mueller, et al.,

243 2001) and depends completely on vegetation foraged by ants for its food. Thus, if lunchbox

244 resources fuel worker foraging, they are analogous to investment in hypha production by

245 ancestral free-living Basidiomycete fungi (Mueller, et al., 2001) that extend hyphae to forage

246 for decaying organic matter on the forest floor. More generally, organisms engaged in

247 symbioses often lose critical functions (Gil, Sabater-Muñoz, Latorre, Silva \& Moya, 2002),

248 and lunchbox dynamics provide a means of eliciting the replacement cooperative behaviour

249 from symbiotic partners. 

dynamics within leafcutter farming symbioses, using radiolabeled tracers $\left(\mathrm{P}^{32}, \mathrm{C}^{14}\right)$ to indirectly track the flow of nutrients from harvested substrate to fungus cultivar to ant farmers. They found some evidence of liquid ingestion when a leaf fragment was placed

254 directly on the fungus garden and when an exposed 'leafy shoot' was provided (Littledyke \& 255 Cherrett, 1976). However, liquid ingestion was not actually detected (or barely detected) among the leafcutter workers cutting leaves in foraging arenas (Littledyke \& Cherrett, 1976). It is also unclear whether any of the $\mathrm{P}^{32}, \mathrm{C}^{14}$ tracers reflected liquid assimilated by adult workers or were simply processed as fecal droplets used to manure fungus gardens. And yet, the idea that foragers consume, transport, and assimilate plant exudates while cutting and 260 preparing leaves has been frequently used to assert that ants consume large amounts of nutrients from outside of their farming symbiosis (e.g. Bass \& Cherrett, 1995; Mueller, et al., 2001; Wirth, et al., 2003).

264 fungi do not provide sufficient nutrition for ant farmers (Bass \& Cherrett, 1995; Mueller, 265 2002; Mueller, et al., 2001), and run counter to major recent advances towards understanding the specialised physiological interplay between ant farmers, their fungal cultivars, and additional microbial partners. For instance, leafcutter ants receive enzymes from ingested

268 fungus that are then passed unharmed through the digestive system and returned to the garden 269 as faecal droplets to manure new garden substrate (De Fine Licht, et al., 2013; Kooij, et al., 270 2014; Martin, 1970; Schiøtt, et al., 2010). Moreover, N-fixing rhizobiales bacteria have been 271 discovered in the leafcutter fungus gardens (Pinto-Tomás, et al., 2009) and the guts of 272 workers (Sapountzis, et al., 2015). Comparing these specialised digestive adaptations in 273 leafcutter workers with their highly simplified crops and proventriculi (Caetano, 1990; Fig. 1) 
strongly supports that leafcutter ants in natural populations lack plant nectar harvesting as a foraging strategy.

We next review prospects for the lunchbox hypothesis, which provides a novel

strategy by which departing foragers can fuel their foraging by dynamically ingesting a short-

278 term pulse of nutrition. First, while only load carriage was associated with liquid depletion in 279 this study, ants may indeed use midgut liquids when the cutting more recalcitrant leaves, or foraging greater distances, especially while climbing trees. Workers may also fuel energetically costly foraging activities with alternative metabolic fuels (e.g. glycogen from fat body cells; Roma, Mathias \& Bueno, 2006). Second, stored liquids were not identified, as 283 leafcutter ants have a sieve-like organ preventing particles with diameter $>10 \mu \mathrm{m}$ from entering their alimentary canals (Mueller, et al., 2001), and this prevented visual inspection of partially digested foods. Third, while we confirm a within-nest origin for lunchbox liquids, a possible retention duration of 10 days (Erthal, Silva \& Samuels, 2004) makes the precise source difficult to ascertain. For instance, exiting workers may directly consume fungi or solicit regurgitated liquids from larvae. It will thus be important to both identify the chemical makeup of lunchbox liquids and the behaviours preceding their acquisition.

Moving forward, lunchbox dynamics can be tested across diverse ant species facing diverse ecological challenges. For instance lunchbox liquids may be limited to ecological specialists with ample within-nest liquid supplies, like leafcutter ants with fungi, species 293 tending exudate-producing hemipterans inside their nests (Hölldobler \& Wilson, 1990), or 294 arid climate species with liquid storage castes (Rissing, 1984). However, such ecological specialisations may also be unnecessary, as ants generally have larvae inside their nests that could provide foragers with regurgitated liquids (Hölldobler \& Wilson, 1990). More

297 generally, the lunchbox hypothesis provides a robust theoretical framework to link foraging 298 energetics, digestive physiology, and symbiotic performance. 


\section{REFERENCES}

300 Araújo, M. D. S., Della Lucia, T. M. C., Lima, C. A, Souza, D. J., \& Petternelli, E. F. (2002).

301 Foraging activity of Acromyrmex laticeps nigrosetosus (Hymenoptera, Formicidae) in

302 Eucalyptus stands. Acta Scientiarum, Biological Sciences, Maringá, 24(5), 1321-1325.

303 Bass, M., \& Cherrett, J. M. (1995). Fungal hyphae as a source of nutrients for the leaf-cutting 304 ant Atta sexdens. Physiological Entomology, 20, 1-6.

305 Bollazzi, M., \& Roces, F. (2011). Information needs at the beginning of foraging: Grass-

306 cutting ants trade off load size for a faster return to the nest. PLoS ONE, 6(3).

307 doi:10.1371/journal.pone.0017667

308 Burd, M., \& Howard, J. J. (2005). Central-place foraging continues beyond the nest entrance:

309 the underground performance of leaf-cutting ants. Animal Behaviour, 70(4), 737-744.

310 Caetano, F. H. (1990). Morphology of the Digestive tract and Associated Excretory Organs

311 of Ants. In R. K. Vander Meer, K. Jaffe, \& A. Cedeno (Eds.), Applied Myrmecology. A

312 World Perspective. (pp. 119-129). Westview press, Boulder.

313 Cherrett, J. M. (1972). Some factors involved in the selection of vegetable substrate by Atta

314 cephalotes (L.) (Hymenoptera: Formicidae) in tropical rain forest. Journal of Animal

315 Ecology, 41(3), 647-660. doi:10.2307/3200

316 Cook, S. C., \& Davidson, D. W. (2006). Nutritional and functional biology of exudate-

317 feeding ants. Entomologia Experimentalis et Applicata, 118(1), 1-10. doi:10.1111/j.1570-

$318 \quad 7458.2006 .00374 . x$ 
319 De Fine Licht, H. H., Schiøtt, M., Rogowska-Wrzesinska, A., Nygaard, S., Roepstorff, P., \&

320 Boomsma, J. J. (2013). Laccase detoxification mediates the nutritional alliance between leaf-

321 cutting ants and fungus-garden symbionts. Proceedings of the National Academy of Sciences,

322 110(2), 583-587. doi:10.1073/pnas.1212709110

323 Dussutour, A., \& Simpson, S. J. (2008). Description of a simple synthetic diet for studying

324 nutritional responses in ants. Insectes Sociaux, 55(3), 329-333. doi:10.1007/s00040-008-

$325 \quad 1008-3$

326 Eisner, T. (1957). A comparative morphological study of the proventriculus of ants

327 (Hymenoptera: Formicidae). Bulletin of the Museum of Comparative Zoology 16, 441-489

328 Eisner, T., \& Brown Jr., W. L. (1958). The evolution and social significance of the snt 329 proventriculus. Proceedings Tenth International Congress of Entomology 2, 503-508.

330 Engel, V., Fischer, M. K., Wäckers, F. L., \& Völkl, W. (2001). Interactions between

331 extrafloral nectaries, aphids and ants: Are there competition effects between plant and 332 homopteran sugar sources? Oecologia, 129(4), 577-584. doi:10.1007/s004420100765

333 Erthal, M., Silva, C. P., \& Samuels, R. I. (2004). Digestive enzymes of leaf-cutting ants, 334 Acromyrmex subterraneus (Hymenoptera: Formicidae: Attini): Distribution in the gut of 335 adult workers and partial characterization. Journal of Insect Physiology, 50(10), 881-891. 336 doi:10.1016/j.jinsphys.2004.06.009

337 Feldhaar, H., Gebauer, G., \& Blüthgen, N. (2009). Stable isotopes: Past and future in 338 exposing secrets of ant nutrition (Hymenoptera: Formicidae). Myrmecological News, 339 13(April), 3-13. 
341 Gil, R., Sabater-Muñoz, B., Latorre, A., Silva, F. J., \& Moya, A. (2002). Extreme genome

342 reduction in Buchnera spp.: Toward the minimal genome needed for symbiotic lifestyle.

343 Proceedings of the National Academy of Sciences, 99(7): 4454-44-58.

344 doi:10.1073/pnas.062067299

345

346 Hughes, W. O. H., Sumner, S., Van Borm, S., \& Boomsma, J. J. (2003). Worker caste 347 polymorphism has a genetic basis in Acromyrmex leaf-cutting ants. Proceedings of the 348 National Academy of Sciences, 100(16), 9394-9397. doi:10.1073/pnas.1633701100.

350 Hölldobler, B., \& Wilson, E. O. (1990). The Ants. Harvard University Press, Cambridge. 351

352 Hölldobler, B., \& Wilson, E. O. (2010). The Leafcutter Ants: Civilization by Instinct. Norton 353 \& Company, New York, NY.

354 Jaffe, K., \& Howse, P. E. (1979). The mass recruitment system of the leaf cutting ant, Atta 355 cephalotes (L.). Animal Behaviour, 27(2), 930-939. doi:10.1016/0003-3472(79)90031-9

356 Josens, R. B., Farina, W. M., \& Roces, F. (1998). Nectar feeding by the ant Camponotus mus:

357 Intake rate and crop filling as a function of sucrose concentration. Journal of Insect

358 Physiology, 44(7-8), 579-585. doi:10.1016/S0022-1910(98)00053-5

359 Kay, A. (2002). Applying optimal foraging theory to assess nutrient availability ratios for 360 ants. Ecology, 83(7), 1935-1944.

361 Kooij, P. W., Rogowska-Wrzesinska, A., Hoffmann, D., Roepstorff, P., Boomsma, J. J., \& 362 Schiøtt, M. (2014). Leucoagaricus gongylophorus uses leaf-cutting ants to vector proteolytic 
enzymes towards new plant substrate. The ISME Journal, 8(5), 1032-40.

doi:10.1038/ismej.2013.231

365 Kooij, P. W., Aanen, D. K., Schiøtt, M., \& Boomsma, J. J. (2014). Differences in forage-

366 acquisition and fungal enzyme activity contribute to niche segregation in Panamanian leaf367 cutting ants. PLoS One, 9(4), 394284.

368 Lanan, M. (2014). Spatiotemporal resource distribution and foraging strategies of ants

369 (Hymenoptera: Formicidae). Myrmecological News, 20(September), 53-70.

370 doi:10.1016/j.biotechadv.2011.08.021.Secreted

371 Lewis, T., Pollard, G. V., \& Dibley, G. C. (1974). Rhythmic foraging in the leaf-cutting ant 372 Atta Cephalotes (L.) (Formicidae:Attini). Journal of Animal Ecology, 43(1), 129-141. 373 doi: $10.2307 / 3162$

374 Lighton, J. R. B., Bartholomew, G. A., \& Feener, D. H. (1987). Energetics of locomotion and 375 load carriage and a model of the energy cost of foraging in the leaf cutting ant Atta 376 colombica. Physiological Zoology, 60(5), 524-537

377

378 Littledyke, M., \& Cherrett, J. M. (1976). Direct ingestion of plant sap from cut leaves by the 379 leaf-cutting ants Atta cephalotes (L.) and Acromyrmex octospinosus (Reich) (Formicidae, 380 Attini). Bulletin of Entomological Research, 66(02), 205-217. doi:10.1017/S0007485300006647

382 Lopes, J. F. S., Forti, L. C., \& Camargo, R. S. (2004). The influence of the scout upon the 383 decision-making process of recruited workers in three Acromyrmex species (Formicidae: 384 Attini). Behavioural Processes, 67(3), 471-476. 
Martin, M. M. (1970). The biochemical basis of the fungus-attine ant symbiosis. Science, 169(3940), 16-20.

Moreira, D. D. O., Bailez, A. M. V, Erthal, M., Bailez, O., Carrera, M. P., \& Samuels, R. I. 388 (2010). Resource allocation among worker castes of the leaf-cutting ants Acromyrmex subterraneus subterraneus through trophallaxis. Journal of Insect Physiology, 56(11), 1665390 1670. doi:10.1016/j.jinsphys.2010.06.018

Mueller, U. G. (2002). Ant versus fungus versus mutualism: Ant-cultivar conflict and the 392 deconstruction of the attine ant-fungus symbiosis. The American Naturalist, 160 Supplement 393 (October), S67-S98. doi:10.1086/342084

Mueller, U. G., Schultz, T. R., Currie, C. R., Adams, R. M. M., \& Malloch, D. (2001). The 395 origin of the attine ant-fungus mutualism. The Quarterly Review of Biology, 76(2), 169-197.

396 Orians, G. H., \& Pearson, N. E. (1979). On the theory of central place foraging. In D. J. 397 Horn, G. R. Stairs, \& R. D. Mitchell (Eds.), Analysis of Ecological Systems. (pp. 155-177). 398 Ohio State University Press.

399 Oster, G. F. \& Wilson, E. O. (1978). Caste and Ecology in the Social Insects. Princeton, NJ: 400 Princeton University Press.

401 Pinto-Tomás, A. A., Anderson, M. A., Suen, G., Stevenson, D. M., Chu, F. S. T., Cleland, W. 402 W., Weimer, P. J. \& Currie, C. R. (2009). Symbiotic nitrogen fixation in the fungus garden of 403 leaf-cutter ants. Science, 326(5956), 1120-1123. doi:10.1126/science.1173036

404 Portha, S., Deneubourg, J. L., \& Detrain, C. (2002). Self-organized asymmetries in ant 405 foraging: a functional response to food type and colony needs. Behavioral Ecology, 13(6), 406 776-781. doi:10.1093/beheco/13.6.776 
407 Pyke, G., Pulliam, H. R., \& Charnov, E. L. (1977). Optimal foraging: A selective review of 408 theory and tests. The Quarterly Review of Biology, 52(2), 137-154.

409 Rissing, S. W. (1984). Replete caste production and allometry of workers in the honey ant, 410 Myrmecocystus mexicanus Wesmael (Hymenoptera: Formicidae). Journal of the Kansas 411 Entomological Society, 57(2), 347-350.

412 Robson, S. K., \& Traniello, J. F. (1998). Resource assessment, recruitment behavior, and 413 organization of cooperative prey retrieval in the ant Formica schaufussi (Hymenoptera: 414 Formicidae). Journal of Insect Behavior, 11(1), 1-22. doi:10.1023/A:1020859531179

415 Roces, F. \& Núñez, J. (1993). Information about food quality influences load-size selection 416 in recruited leaf-cutting ants. Animal Behaviour, 45(1), 135-143.

417 Roces, F., \& Lighton, R. B. (1995). Larger bites of leaf-cutting ants. Nature, 373, 392-393

418 Roma, G. C., Mathias, M. I. C., \& Bueno, O. C. (2006). Fat body in some genera of leaf419 cutting ants (Hymenoptera: Formicidae). Proteins, lipids and polysaccharides detection. 420 Micron, 37(3), 234-242. doi:10.1016/j.micron.2005.10.012

421 Sapountzis, P., Zhukova, M., Hansen, L. H., Sørensen, S. J., Schiøtt, M., \& Boomsma, J. J. 422 (2015). Acromyrmex leaf-cutting ants have simple gut microbiota with nitrogen-fixing 423 potential. Applied and Environmental Microbiology, 81(16), 5527-5537.

424 Schiøtt, M., Rogowska-Wrzesinska, A., Roepstorff, P., \& Boomsma, J. J. (2010). Leaf425 cutting ant fungi produce cell wall degrading pectinase complexes reminiscent of 426 phytopathogenic fungi. BMC Biology, 8(1), 156. doi:10.1186/1741-7007-8-156 
427 Stephens, D. W., Brown, S. J., \& Ydenberg, R. C. (2007) Foraging: Behavior and Ecology.

428 Chicago: University of Chicago Press.

429 Stephens, D. W. \& Krebs, J. R. (1986) Foraging theory. Princeton: Princeton University 430 Press.

431 Wetterer, J. K. (1994). Forager polymorphism, size-matching, and load delivery in the leaf432 cutting ant, Atta cephalotes. Ecological Entomology, 19, 57-64.

433 Wetterer, J. K. (1995). Forager size and ecology of Acromyrmex coronatus and other leaf434 cutting ants in Costa Rica. Oecologia, 104(4), 409-415. doi:10.1007/BF00341337

435 Wilson, E. O. (1980). Caste and division of labor in leaf-cutter ants (Hymenoptera:

436 Formicidae: Atta). Behavioral Ecology and Sociobiology, 7, 157-165.

437 Wirth, R., Herz, H., Ryel, R. J., Beyschlag, W. \& Hölldobler, B. (2003). Herbivory of leaf438 cutting ants: A case study on Atta colombica in the tropical rainforest of Panama. Berlin, 439 Heidelberg: Springer. 
442 FIGURE 1 Leafcutter ant digestive system, highlighting the three connected storage organs

443 (crop, midgut, hindgut) described in the text. (a) Dorsal view of storage organs in a partially

444 dissected Ac. echinatior worker abdomen showing a full hindgut and midgut and empty crop

445 (white spheres are fat body cells). (b) Lateral view of fully dissected At. sexdens digestive

446 system showing a midgut full with the characteristic yellow fluid flanked by an empty crop

447 and hindgut. (c) Schematic illustration of the digestive system highlighting key digestive

448 organs: E, oesophagus, C, crop; Pr, proventriculus; M, midgut; Mt, malphigian tubules; Il,

449 Ileum; H, Hindgut; Rp, Rectal pads; A, anus. Images viewed at 250X magnification.

450 FIGURE 2 Field observations of foraging rates across four leafcutter ant species. Data points 451 indicate percentage of workers returning to their nests unladen (without carrying vegetation 452 in their mandibles). Observations were performed over $374 \mathrm{~min}$ for Ac. echinatior (365 453 returning ants), $151 \mathrm{~min}$ for Ac. octospinosus (130 returning ants), $18 \mathrm{~min}$ for At. colombica 454 (2 679 returning ants), and 18 min for At. sexdens (2 078 returning ants). Means provided $455 \pm$ SD. Head size scale bars represent $0.5 \mathrm{~mm}$. Ant images are from antweb.org.

456 FIGURE 3 Similarities in liquid transport dynamics across four leafcutter ant species.

457 Columns show percentage of full crops (black), midguts (light grey), and hindguts (dark 458 grey) from dissections performed on a total of 670 field-collected foragers (Ac. echinatior: 459 161, Ac. octospinosus: 114, At. colombica: 200, At. sexdens: 195). Least square means 460 provided (+SE).

461 FIGURE 4 The effects of load carrying ( $0 \mathrm{mg}$ vs. $10 \mathrm{mg}$ ) and foraging distance (2 m vs. 10 $462 \mathrm{~m}$ ) on liquid transport dynamics in (a) crops, (b) midguts, and (c) hindguts of Ac. echinatior 463 foragers in laboratory experiments. Least square means plotted $\pm \mathrm{SE}$. 
464 TABLE 1 Results of mixed model analyses testing for variation in the proportion of

465 leafcutter ant foragers with full storage organs (crop, midgut, hindgut) in both field

466 observations in a Panamanian rainforest and in laboratory experiments.

\begin{tabular}{|lllll|}
\hline Effect & Num DF & Denom DF & $F$ & $P$ \\
Field liquid transport & & & & \\
Species & 3 & 10.99 & 0.42 & 0.744 \\
Foraging status & 2 & 65.34 & 1.32 & 0.274 \\
Species x foraging status & 6 & 65.21 & 0.27 & 0.949 \\
Organ & 2 & 45.45 & 121.17 & 0.0001 \\
Species x organ & 6 & 53.83 & 1.44 & 0.215 \\
Foraging status x organ & 4 & 50.94 & 5.10 & 0.002 \\
Species x foraging status x organ & 12 & 56.51 & 0.59 & 0.839 \\
& & & & \\
Distance x load mass experiment & 1 & & & \\
Load mass treatment & 1 & 10.63 & 17.46 & 0.002 \\
Foraging distance treatment & 1 & 10.63 & 1.16 & 0.306 \\
Load mass x distance & 2 & 7.91 & 2.55 & 0.139 \\
Organ & 2 & 7.91 & 202.91 & 0.0001 \\
Load mass x organ & 2 & 7.91 & 0.02 & 0.337 \\
Distance x organ & 2 & 7.91 & 1.21 & 0.980 \\
Load mass x distance x organ & & & & \\
& & & & \\
Leaf-cutting experiment & 1 & 12.84 & 0.99 & 0.338 \\
Cutting treatment & 2 & 7.204 & 52.95 & 0.0001 \\
Organ & 2 & 7.204 & 0.61 & 0.569 \\
Cutting treatment x organ & & & & \\
\hline
\end{tabular}

467 The analysis is based on field observations comparing liquid storage across four leafcutter

468 species (At. colombica, At. sexdens, Ac. echinatior, Ac. octospinosus) and foraging statuses

469 (laden: carrying a fragment of vegetation, unladen: empty mandibles, exiting: exiting nest). In

470 the distance and load transport experiment, we compared liquid storage across load transport

471 treatments (control, $10 \mathrm{mg}$ ) and distance treatments $(2 \mathrm{~m}, 10 \mathrm{~m})$. In the leaf-cutting

472 experiment analysis, we compared liquid storage across leaf-cutting treatments (cutting:

473 having just cut a leaf fragment, control: having just exited the nest). 

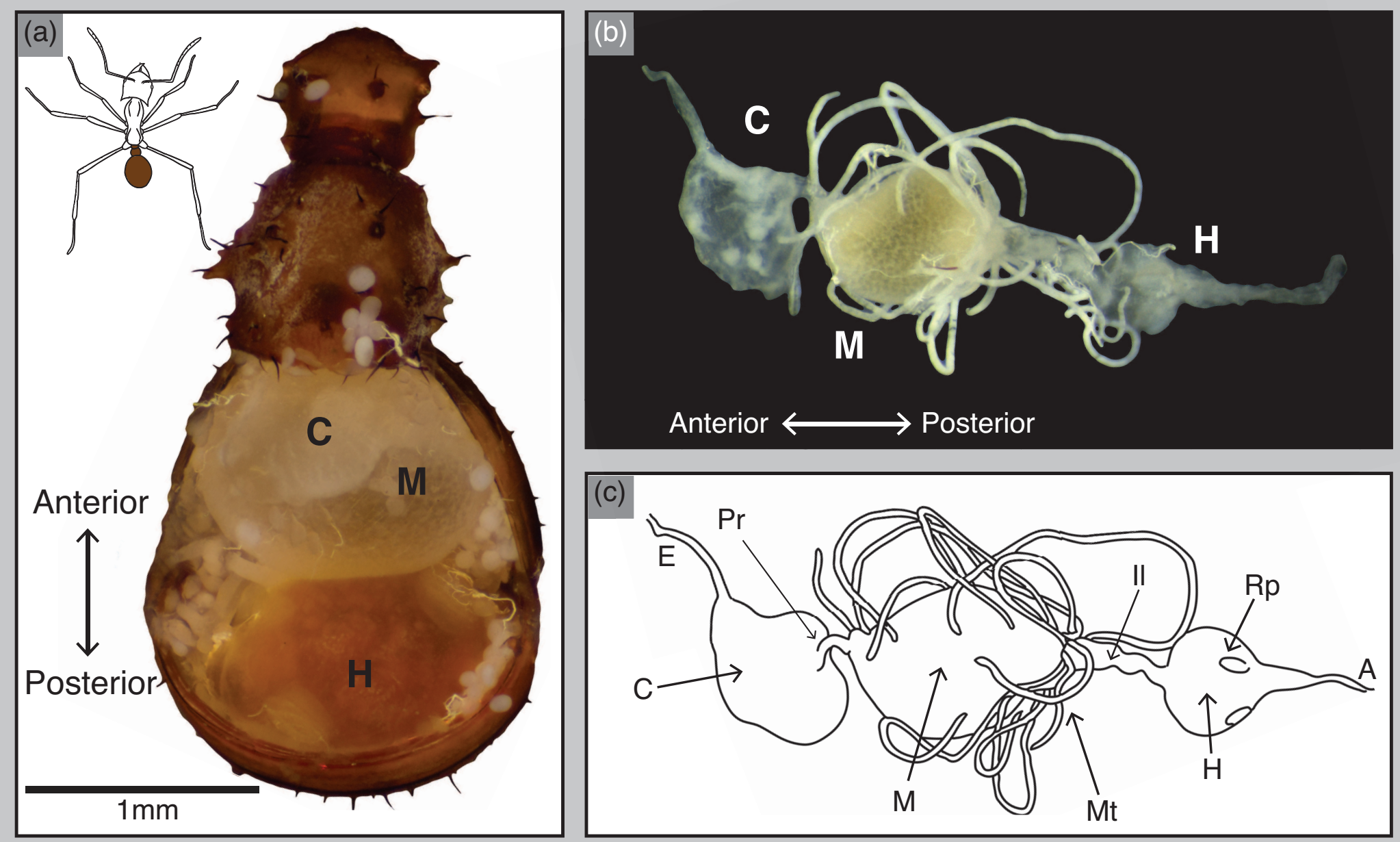


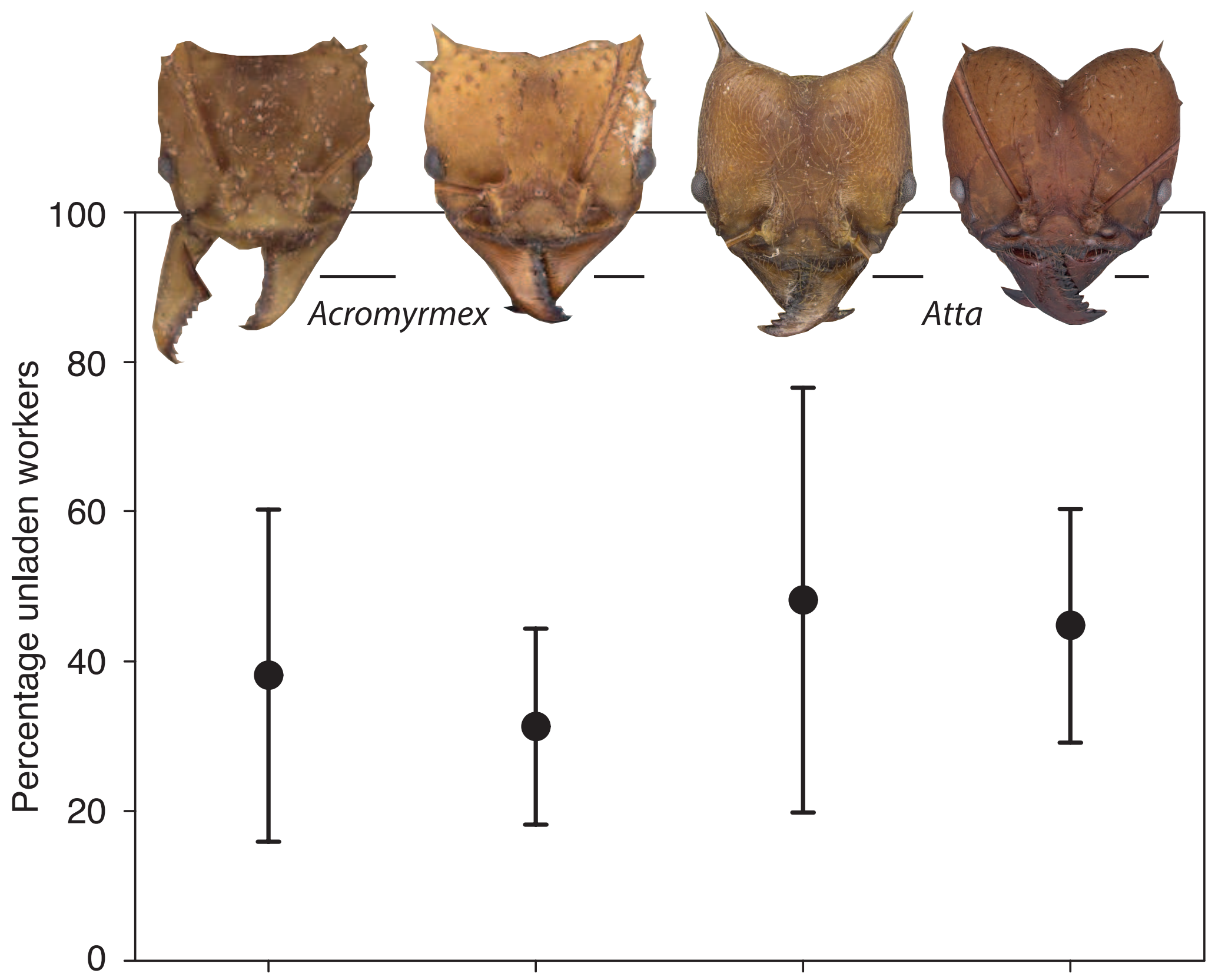

Ac. echinatior Ac. octospinosus At. colombica At. sexdens 
Figure
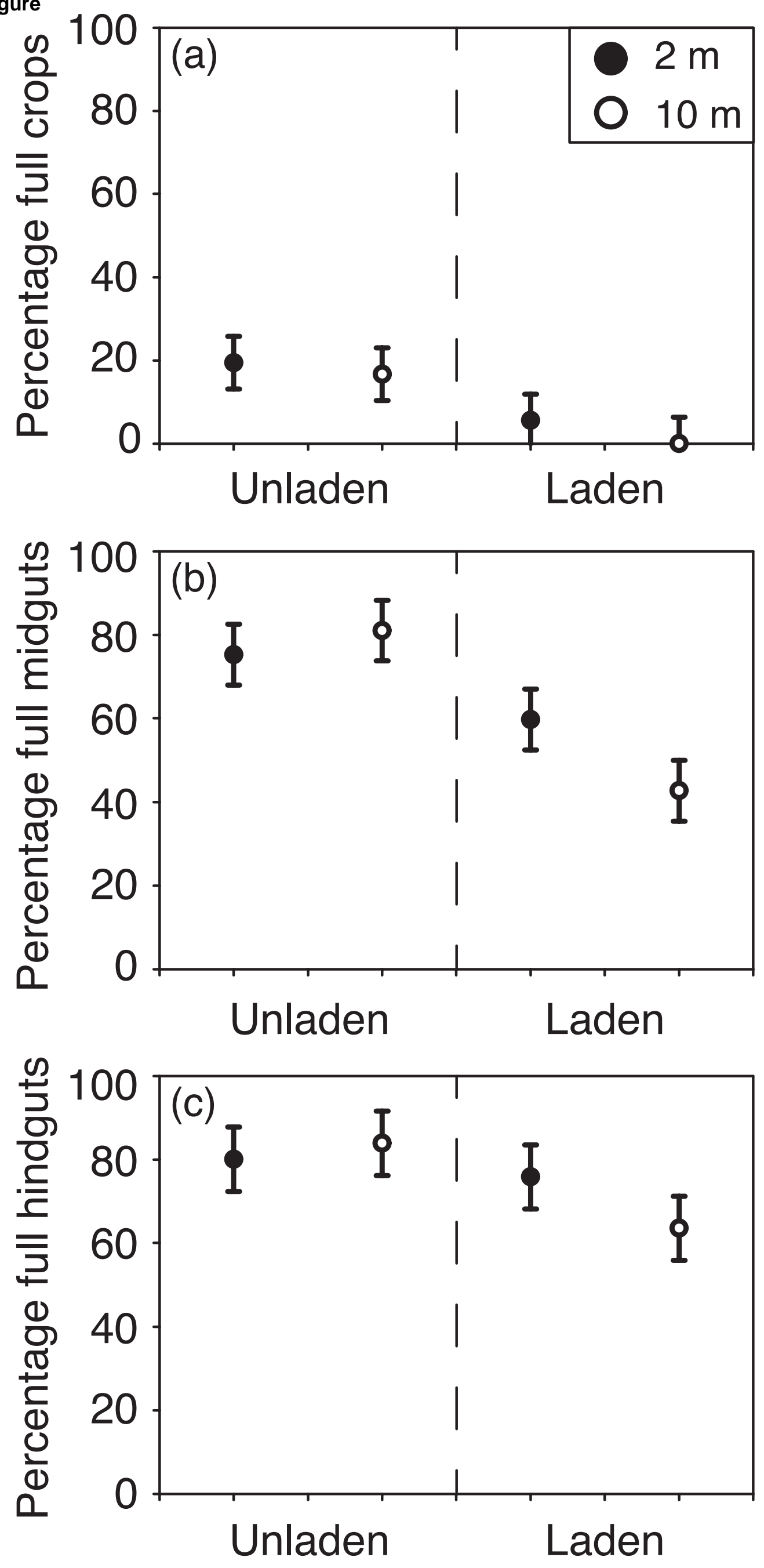